\title{
Novel Assay Analyzing Tropism between Adipose-Derived Stem Cells and Breast Cancer Cells Reveals a Low Oncogenic Response
}

\author{
Matthias A. Sauter ${ }^{a} \quad$ Elizabeth Brett ${ }^{a} \quad$ Christina M. Müller ${ }^{a}$ b Hans-Günther Machens ${ }^{a}$ \\ Dominik Duscher ${ }^{\mathrm{a}}$ \\ ${ }^{a}$ Department of Plastic and Hand Surgery, Technical University Munich, Munich, Germany; \\ ${ }^{\mathrm{b}}$ Ludwig-Maximilian-University Munich (LMU), Munich, Germany
}

Keywords

Adipose-derived stem cells · Tropism - Breast cancer .

MDA-MB-231 · MCF-7 · Oncogenic risk · Dormancy

\begin{abstract}
Introduction: In the surgical world of breast cancer reconstruction, fat grafting is commonly viewed as an oncogenic risk. Scientific studies add confusion, given the stark lack of clinical evidence suggesting pro-oncogenic links. Typically, classic migration assays (e.g., Boyden chamber) between adipose-derived stem cells and breast cancer cells define this cell relationship as pro-oncogenic. Objective: We sought to develop a new migration model which better explains existing clinical data. Methods: Silicon chambers were used to seed isolated populations of cells simultaneously in culture dish. Once cells had adhered, chambers were removed and cells were allowed to follow natural trophic cues. Multiple permutations of MDA-MB-231, MCF-7, HS-27, and ASCs were engineered. Cells were stained with MitoTracker for fluorescent visualization. A human cytokine array (RayBiotech) was performed on the media of migrating assays. Cellular tropism and blot intensity were quantitatively measured in Image J. Results: An in vitro model was successfully constructed where ASCs reproducibly and freely migrated. Cytokine arrays reveal higher levels of IL- 6 and CCL2 in the media of Boyden chambers containing ASCs and MDA-MB-231, com-
\end{abstract}

\section{KARGER}

() 2019 S. Karger AG, Basel pared to the novel assay, comprised of the same cell numbers, types, and incubation times. Conclusion: These data collectively show for the first time the attraction of ASCs to malignant breast cancer cells; a phenomenon which many ASC studies infer. The cytokine profile of the novel system described is less oncogenic than the commonly described Boyden chamber. These data integrate better into the clinical data, which fail to link cancer recurrence with fat grafting.

(c) 2019 S. Karger AG, Basel

\section{Introduction}

The migration of stem cells is a frequent topic in tissue regeneration. It is the objective of many regenerative therapies to attract, sequester, and populate tissues/structures with stem cells, native or transplanted $[1,2]$. Conversely, it is one of the main mechanics for which stem cells have been called "dangerous," and is the chief reason why they have yet to be federally regulated for clinical use [3]. Specifically, the aversion to stem cell use is the undesired and unpredictable relocation of the cells to zones where their effect is harmful. The effect could be as erratic as dormancy, hyperplasia, differentiation, and proinflammation $[4,5]$. By far the most widely feared consequence is oncogenicity, merging the field of stem cell regenerative medicine with cancer biology. 
Autologous breast reconstruction illustrates the issue with the unknown migration pattern of stem cells. A commonly used technique is fat grafting - the injection of liposuction aspirate in order to restore volume and shape. Grafted fat contains multiple cell compartments, including the stromal vascular fraction population (the cellular compartment within adipose tissue which is not endothelial cell or adipocyte) $[6,7]$. The stromal vascular fraction in turn contains a multipotent population called adiposederived stem cells (ASCs). The technique of fat grafting is accepted clinical practice in breast reconstruction, and is generally a conflict-free procedure in healthy patients [8]. However, for patients who seek breast reconstruction after cancer treatment, there exists significant surgical caution around fat grafting. Specifically, there is concern that the pro-angiogenic [9], pro-survival [10], tissue regenerative [2] properties of ASCs would be transferred to existing cancer cells, stimulating recurrence [11].

Several existing experimental studies describe the coculture and crosstalk of breast cancer cells (BCs) and ASCs, specifically as drivers of recurrence [12-14]. Certain research has investigated crosstalk of BCs and ASCs $[15,16]$, describing migration through transwell membranes or in vitro $2 \mathrm{D}$ scratches. Although these assays examine the one-way relationship of cell migration over time, the dynamics of cell-cell attraction remain unclear.

The pull of stem cells (e.g., mesenchymal and adiposederived stem cells, MSCs/ASCs) to the tumor body has been well investigated and described in the literature, but can have two diametrically opposed meanings. In a 2017 study, cancer oncology viewed the MSC as a therapy; a vehicle for cytotoxic agents into the tumor using ASCs as a native cell conduit [17]. However, oncoplastic surgery sees the infiltration of stem cells to a tumor site as a major danger - the source of recurrence risk [15]. This clinical fear is especially puzzling given the stark lack of evidence showing causation of recurrence by fat grafting (supply of ASCs to a postcancerous zone) [18-20]. Multiple in vitro and in vivo studies elude to migration of MSCs towards tumors $[17,21,22]$, yet there is no clear depiction of this phenomenon, much less a way to examine it between cancers of different malignancies.

Existing assays measure migration with transwell inserts, Matrigel invasion assays, and scratch assays with 2 cell types. While these are educational, they are restrictive on the real tropism the cells may have. The present study demonstrates an undescribed set of in vitro cellular arrangements, which allow the study of unbiased trophics between ASCs, fibroblasts, and BCs. In our described set of models, cells are allowed to follow natural cues, compared to a constructed assay which allows for only oneway migration.

The kinetics between benign/malignant BCs and ASCs have defined the largely negative psychology surrounding breast cancer reconstruction using autologous fat. The goal is to visualize the stem cell movement phenomenon to which so many fat grafting studies refer. We use a unique clinical context to frame our work - ASC attraction to breast cancer - in the hypothesized model of ASCrelated breast cancer relapse.

\section{Materials and Methods}

\section{Cell Acquisition, Culture, and Staining}

The BC lines MDA-MB-231 (triple negative, malignant cancer), MCF-7 (benign cancer), and fibroblast cell line HS-27 were purchased from ATCC. Human ADCs were purchased from Lonza. MDA-MB-231 and HS-27 cells were cultured in DMEM (Biochrom), supplemented with 10\% FBS (Biochrom) and 1\% antibiotic/antimycotic (penicillin G, streptomycin, and amphotericin C) (Capricorn Scientific). ASCs were cultured in Stem MACS ${ }^{\mathrm{TM}}$ MSC Expansion Media (Miltenyi Biotec) supplemented with $1 \%$ of antibiotic/antimycotic. The medium was changed every 2-3 days, and cells were passaged after reaching $80-90 \%$ confluence with $0.25 \%$ trypsin/EDTA (Biochrom). All cells were maintained at $37^{\circ} \mathrm{C}$ in a humidified atmosphere containing $5 \% \mathrm{CO}_{2}$.

Prior to co-culture and population setup MDA-MB-231 cells were stained with Mitotracker CMXRos and HS-27 and ASCs were stained with Mitotracker Red Green FM (Thermo Fischer) according to the manufacturer's protocol. Briefly, stock was dissolved in DMSO in a 1-mM concentration. The stock solution was added to the culture media 1:2,000 (red) and 1:10,000 (green) to an end concentration of $500 \mathrm{nM}$. Cells were then incubated for $4 \mathrm{~h}$, then washed and prepared for in vitro co-culture arrangement.

\section{Models of in vitro Cell Migration}

All structures of in vitro cell migration are described schematically in Figure 1. All cells seeded in the Ibidi chambers were given $12 \mathrm{~h}$ to attach and grow before experimental conditions began.

Three silicon spacing chambers (Ibidi) were arranged in 1 well of a 6-well plate; a cancer population was seeded in the center, ASCs were seeded perpendicular to the right, and fibroblasts perpendicular to the left of the cancer cells. The experiment began with removal of all 3 chambers and adding $2 \mathrm{~mL}$ of media to the well (6-well plate) (Fig. 1A).

In order to challenge the cell attraction dynamics observed with a distance of $1,000 \mu \mathrm{m}$, three silicon spacing chambers (Ibidi) were placed in 1 well of a 6-well plate in a triangular shape. In detail, a discrete BC population was seeded $15 \mathrm{~mm}$ away from ASCs (seeded $70^{\circ}$ to the left) and fibroblasts (seeded $120^{\circ}$ to the right). MDAMB-231 cells were seeded in a density of 10,000 per chamber, and the HS-27 and ASCs were seeded at a density of 12,000 per chamber (Fig. 1B).

Once the seeded cells had the 12-h attachment period, the chamber surrounding the ASCs was removed, while the chamber bordering the BCs remained. The well was flooded with media, allowing a paracrine connection between the populations (Fig. 1C).

After $24 \mathrm{~h}$ the chambers were lifted, and pictures were taken via fluorescence and brightfield microscopy at 5 time points over a period of $48 \mathrm{~h}$. Fluorescent images were quantified using pixel densitometry (ImageJ).

Cytokine Array

To test the paracrine environment of the migrating cell types, we used a Human Cytokine Array (C5) from RayBiotech (https:// www.raybiotech.com/c-series-human-cytokine-array-5-2/). Groups contained the same cell numbers, types, incubation times, 

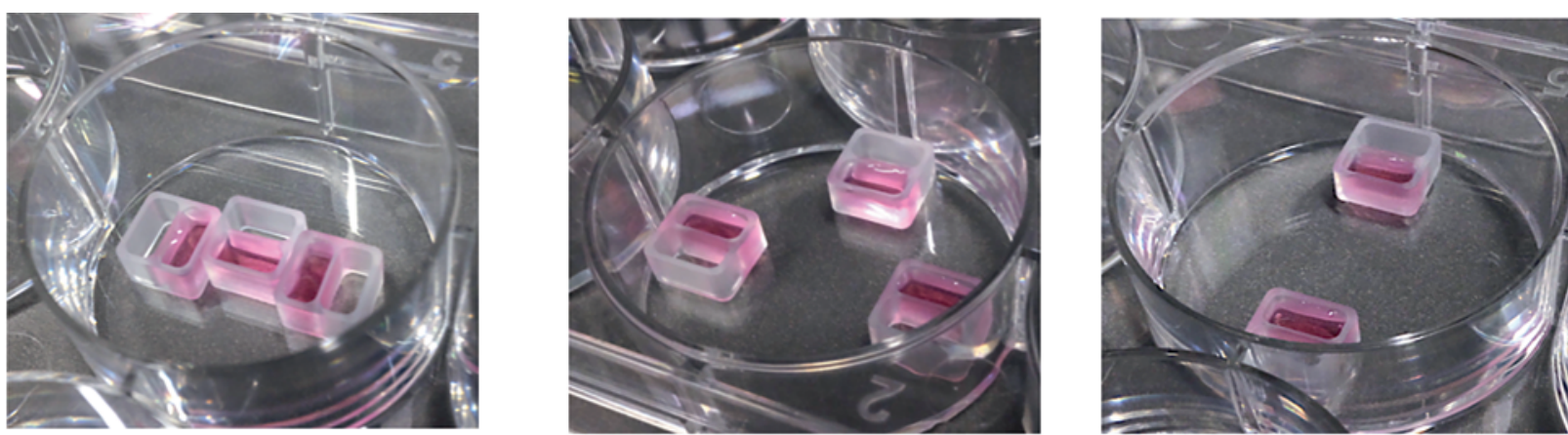

A

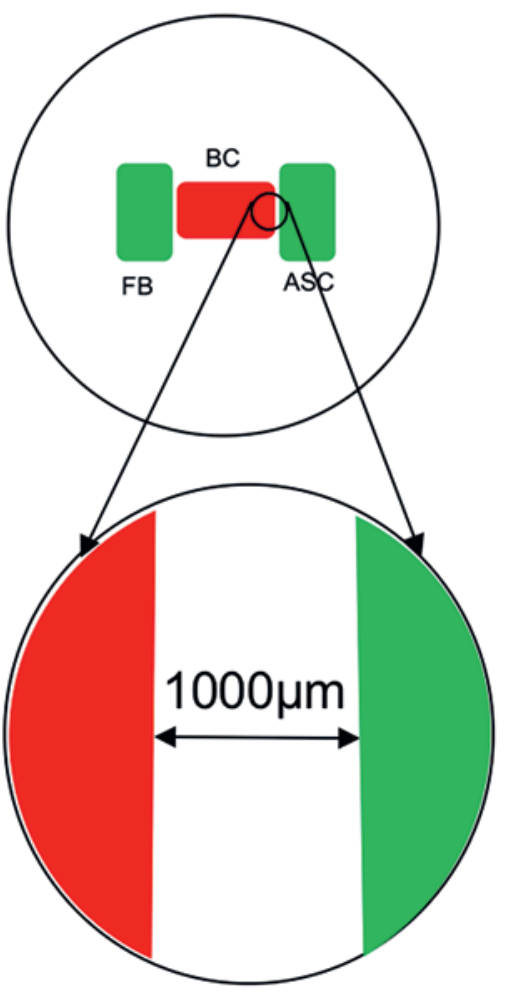

$\mathrm{B}$

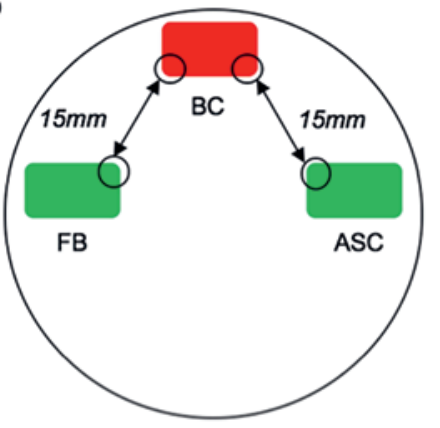

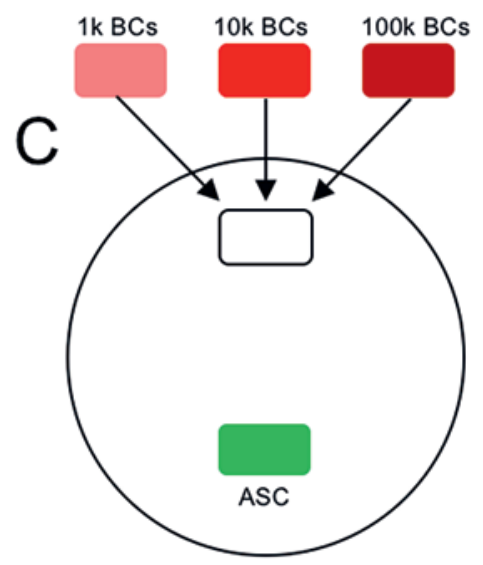

Fig. 1. A In vitro setup of Ibidi chambers, featuring a centrally placed horizontal chamber for BC cell seeding, flanked left and right by vertical chambers for ASC and fibroblast seeding, respectively. B In vitro setup of chambers such that a topmost chamber is placed for $\mathrm{BC}$ cell seeding; $15 \mathrm{~mm}$ away, there is one chamber to the left and one to the right for ASC and fibroblast seeding, respec- tively. C In vitro arrangement of chambers, such that there is a topmost chamber placed for BC seeding, and a bottommost chamber for ASC seeding. The number of the BCs seeded varied from 1,000 to 10,000 to 100,000 , in a model of measuring dose-dependent migratory response from the ASCs. and media volumes. For both a Boyden chamber assay (MDAMB-231 cells seeded in the chamber, ASCs seeded below) and the novel assay, 20,000 ASCs and 15,000 MDA-MB-231 cells were cultured in $1.5 \mathrm{~mL}$ of media containing $1 \% \mathrm{FBS}$, for $48 \mathrm{~h}$. Both groups had $n=3$. At $48 \mathrm{~h}, 333 \mu \mathrm{L}$ of each sample was taken and pooled to form $1 \mathrm{~mL}$ of test solution. Pooled media was added to the blot per manufacturer's instructions. Blots were measured using a BioRad ChemiDoc ${ }^{\mathrm{TM}}$ MP Imaging System and exposed for $15 \mathrm{~s}$.

\section{Statistics}

Data are presented as the mean \pm standard deviation. Twotailed Student's $t$ tests were used to perform direct comparisons between two groups, with corrections for multiple comparisons. A $p$ value $<0.05$ was considered statistically significant. All statistical analyses were performed using GraphPad Prism software (GraphPad Software Inc., La Jolla, CA, USA; http://www.graphpad.com). 


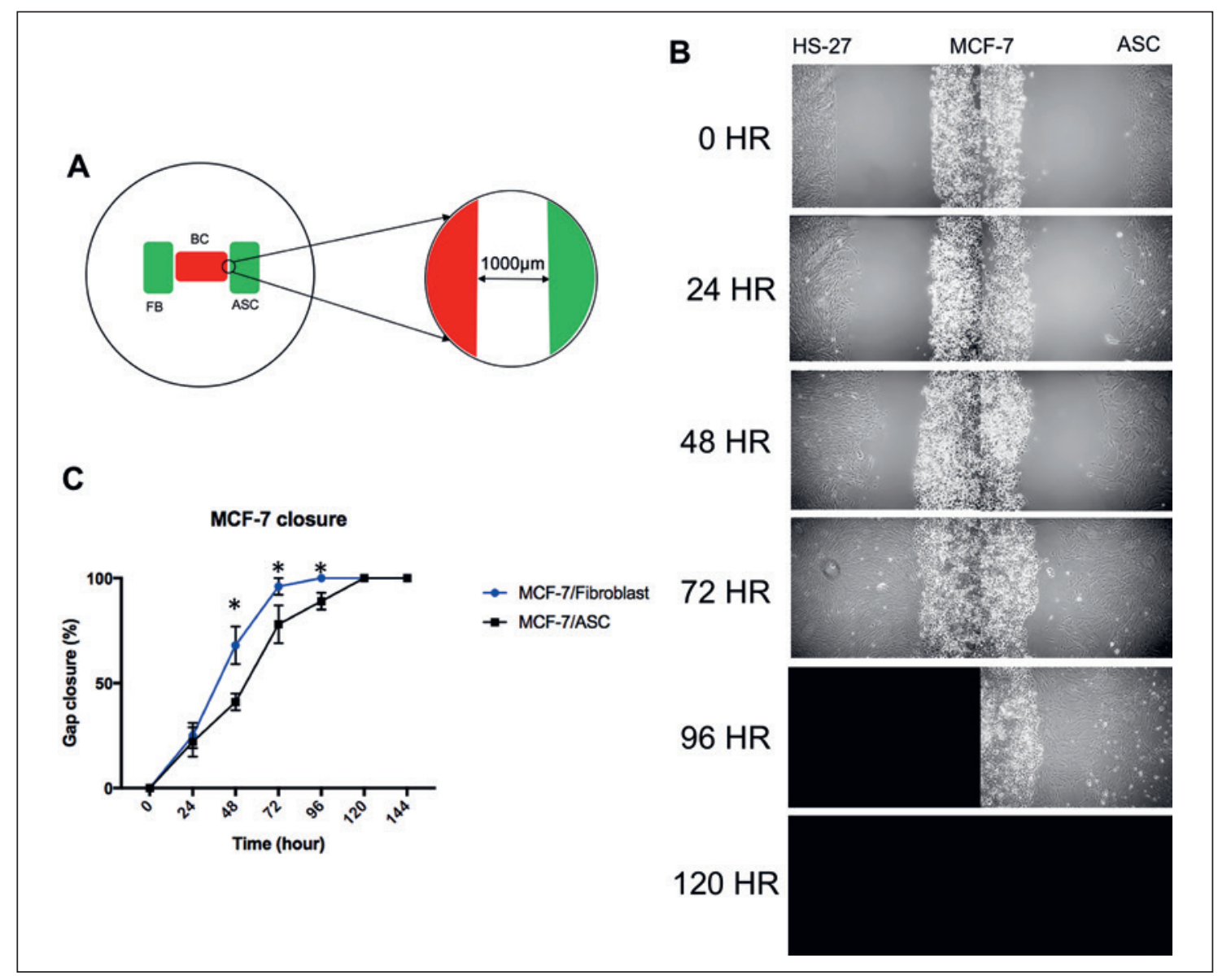

Fig. 2. A These data represent results from the in vitro setup described in Figure 1A. B Brightfield images show a centrally seeded population of MCF-7 BCs between HS-27 fibroblasts on the left and ASCs on the right. Six time points are shown. Gap length at
$0 \mathrm{~h}$ is $1,000 \mu \mathrm{m}$. C Quantification of the gap closure showed significant differences at 48, 72, and $96 \mathrm{~h}$, with the MCF-7/fibroblast group closing fastest at $96 \mathrm{~h}$, and the MCF-7/ASC group closing one time point later, at $120 \mathrm{~h}$. Significance was set at $p<0.05$.

\section{Results}

Fibroblasts and ASCs Are Equally Attracted to MCF-7 Cells, while the MCF-7 Population Remains Static

Per the co-culture model depicted in Figure 2A, MCF-7 cells were seeded centrally between ASCs (right) and fibroblasts (left). When the physical walls were removed from the arrangement, the fibroblast/MCF-7 gap closed faster than the ASC/MCF-7 gap (closed by $96 \mathrm{~h}$, compared to 120 for ASC/MCF-7) (Fig. 2B). However, this difference was not significant with gap closure quantification, and both groups were closed by $120 \mathrm{~h}$ of culture ( $p=0.102)$ (Fig. 2C). Importantly, the MCF-7 population remained largely static during this phase, which serves as an interesting contrast for the same assay with an aggressive cancer type.

MDA-MB-231 Translocate to Static Fibroblasts, while ASCs Are Significantly Attracted

Per the co-culture model depicted in Figure 1A, MDAMB-231 cells were seeded centrally between ASCs (right) and fibroblasts (left). While there was clear migration of
ASCs towards the cancer cell population by $48 \mathrm{~h}$, the fibroblasts opposite migrated less across the $1,000-\mu \mathrm{m}$ gap (Fig. 3A). Quantification of pixel densitometry of the remaining MDA-MB-231 cells in the center showed a significant depletion of cancer cells on the fibroblast side after $36 \mathrm{~h}(p=0.037)$ (Fig. 3B). Gap closure was fastest between MDA-MB-231/fibroblasts compared to MDA-MB-231/ ASCs, with the ASC/MDA-MB-231 gap significantly slower at $72 \mathrm{~h}$, and the MDA-MB-231/fibroblast gap significantly faster at $96 \mathrm{~h}(p=0.027)$ (Fig. 3C). Taken in totality, the gap closure for ASCs and fibroblasts with MCF-7 cells was completed by day 5 , while the closure of the same gap but with MDA-MB-231 was completed by $48 \mathrm{~h}$.

\section{Static MDA-MB-231 Cells Stimulate Strong Migration of ASCs over Distance}

Cells seeded in configuration shown by Figure 1B allow examination of cell migration over distance. When the $\mathrm{BC}$ population was MCF-7, there was little motility shown in both the fibroblasts and ASCs. As seen in Figure 4A, neither cell type shows appreciable migration, and neither leaves 


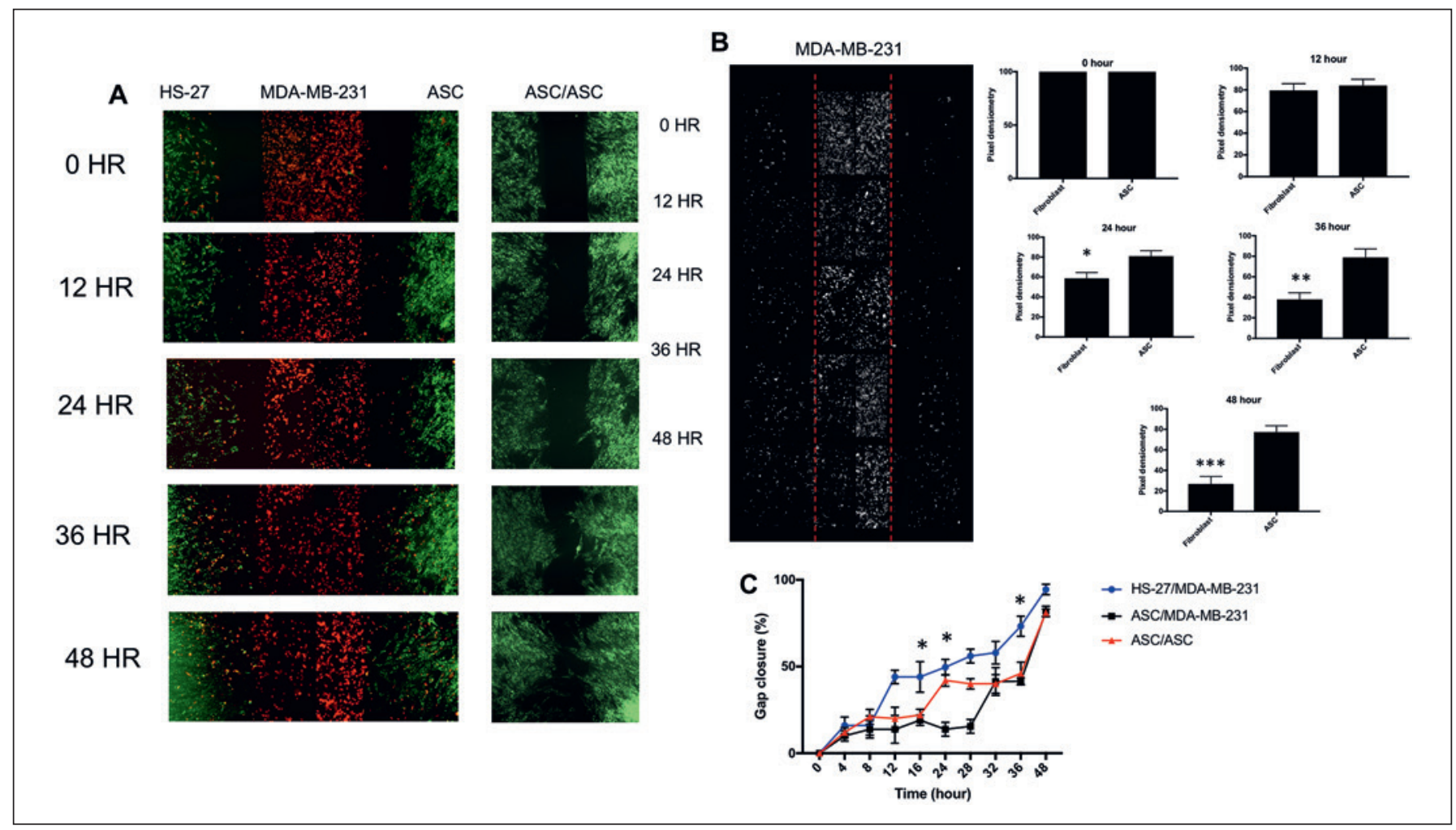

Fig. 3. A These data represent results from the in vitro setup described in Figure 1A. Fluorescent images show a red centrally seeded population of MDA-MB-231 BCs between HS-27 fibroblasts on the left and ASCs on the right. Time points show movement of red BCs out of original boundaries and towards fibroblasts, and a conversely static red BC population with attraction of green ASCs.

the original boundary of seeding (shown by white dotted line). However, when MDA-MB-231 BCs were seeded, a clear initiation of movement by the ASCs was observed in the direction of the cancer cell population after $12 \mathrm{~h}$. Meanwhile, the fibroblast population remained within its original boundaries (shown by dotted line) (Fig. 4B).

\section{Migration of ASCs near BCs Is Dose Dependent, \\ Chiefly with Aggressive Cancer Type}

Cell culture in the configuration of Figure 1C allows observation of cell migration under the influence of different doses of cancer cells. ASCs showed higher migratory behavior when cultured with 100,000 MCF-7 cells, compared to 1,000 MCF-7 cells (Fig. 5A). When ASCs were cultured opposite MDA-MB-231 cells, this effect was more pronounced. ASCs showed comparable migration when cultured with 100,000 MCF-7 cells to that with 1,000 MDA-MB-231 cells (Fig. 5B).

\section{Boyden Chamber Shows 2 Upregulated Cytokines Upstream of Oncogenic Pathways}

The cytokine array showed a high content of IL- 6 and CCL2 (C-C chemokine ligand 2) in the Boyden chamber

B Binary images of red fluorescent stain and quantification thereof by ImageJ. At 24, 36, and $48 \mathrm{~h}$, the depletion of red fluorescence on the side of the fibroblasts is significant compared to the side facing the ASCs. ${ }^{*} p<0.05$. C Quantification of the gap closure revealed an insignificantly different speed of closure between the MCF-7/fibroblast group and the MCF-7/ASC group. ${ }^{*} p>0.05$.

assay compared to the novel assay. Brightfield microscopy showed a marked migration visible halfway through the incubation time, at $24 \mathrm{~h}$ (Fig. 6A). Schematics show the cellular layout, and blue arrows show the direction of travel for the cell types (top half: Boyden chamber, migrating ASCs in yellow seeded on top, MDA-MB-231 cells in red seeded below; bottom half: novel assay setup yellow ASCs migrating towards a static population of red MDA-MB-231 cells). Heat maps represent an overview of the cytokine blots, and main differences are highlighted in red circles (Fig. 6B). Cropped images from the blots are shown in the bottom right (Fig. 6C). IL-6 and CCL2 are both more present in the Boyden chamber.

\section{Discussion}

It is counter-intuitive to create one tissue culture well containing 3 physically defined populations of different cell types, without generating undiscernible, chaotic movement. Instead, the models presently described exhibited replicable, specific motility between populations. Importantly, the 3 cell types had paracrine crosstalk dur- 
MCF-7 cells

$\mathrm{FB}$

A
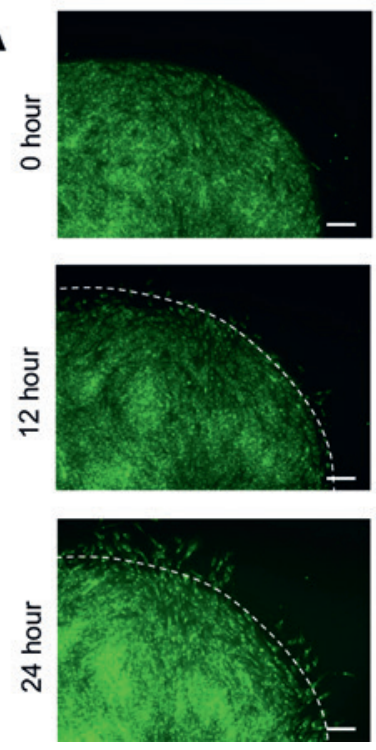

ASC
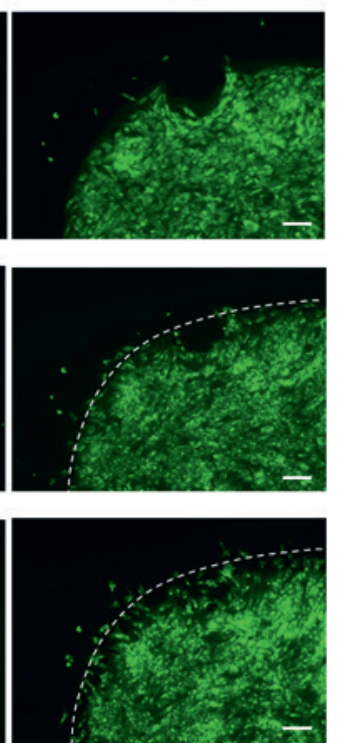

MDA-MB-231 cells

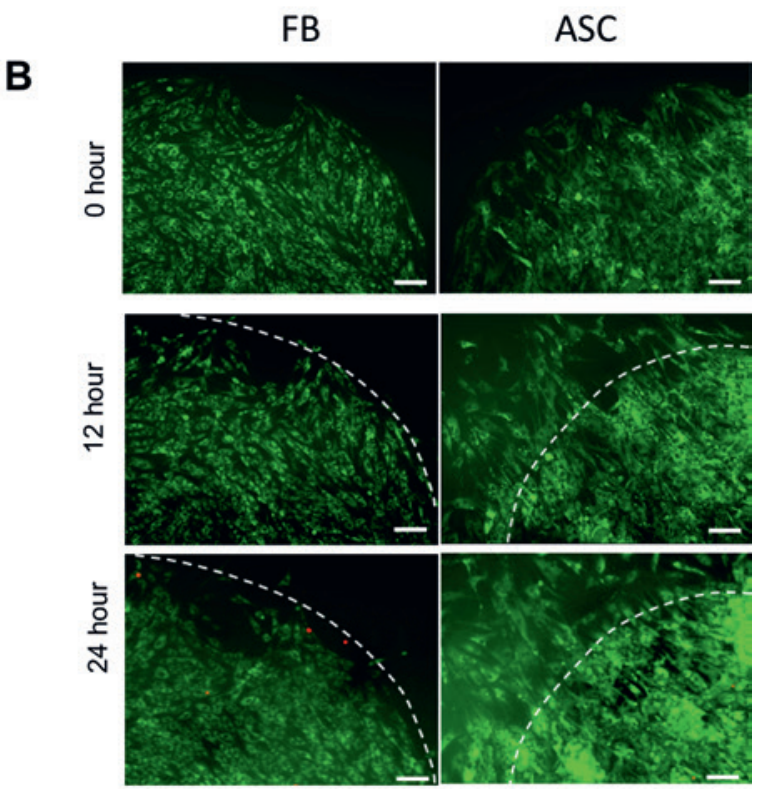

Fig. 4. Data represent results from the in vitro setup described in Figure 1B. A MCF-7 cells were seeded in the topmost chamber, with HS-27 fibroblasts $15 \mathrm{~mm}$ to the left and ASCs $15 \mathrm{~mm}$ to the right. White dotted lines represent the original boundaries of the chamber. Images from 12 and $24 \mathrm{~h}$ show minimal growth of both cell types from the initial boundaries. B An identical setup to that in $\mathbf{A}$ but with MDA-MB-231 BCs seeded rather than MCF-7 cells shows a large activation of ASCs in the direction of the BCs, compared to the fibroblasts. White dotted lines represent the original boundaries of the chamber. Scale bars, $100 \mu \mathrm{m}$. ing these experiments, mimicking the cytokine transfer which these cells experience in vivo.

When combined as 2 cell types in $2 \mathrm{D}$ culture, there is no doubt that cancer cells derive a pro-mitotic, pro-migratory, pro-invasive impact from ASCs. Indeed, it seems that co-culture of BCs with epithelial cells [23], osteoblasts [24], or fibroblasts [25] also gives BCs a boost in mitotic and invasive capacity. Conversely, provision of ASCs to renal epithelial cells [26], tenocytes [27], or chondroblasts [28] similarly results in joined upregulation of cell activity. This is an example of the limitation of this commonly accepted in vitro system: uniaxial measurements and use of only 2 cell types. While studying BCs and ASCs, it is interesting to create a flexible culture system which allows free migration.

With a high-grade BC type (MDA-MB-231), there is undeniable migration of ASCs to a static MDA-MB-231 population, which has been described several times in vivo (monocyte chemoattractant protein 1 secreted by cancer cells draws ASCs) [29] and in vitro (increased lamellipodia extrusion by ASCs when cultured opposite MDA-MB-231 cells) [30]. This was mirrored in an animal model, where circulating ASCs homed to MDAMB-231 tumor bodies [31]. No such evidence exists for tumors of a lower malignancy grade; one study acknowledges that it is easier for an MCF-7 cell to use ASCs in its microenvironment rather than to recruit stem cells from bone marrow. Specifically, MCF-7 cells do not specialize in active stimulation of ASC migration [32].

We also saw in the in vitro setup translocation of MDA-MB-231 cancer cells to the fibroblast population. This mirrors closely the preferential metastasis of invasive cancer to fibroblast-dense organs, e.g., $60 \%$ of metastatic breast cancer develops in the lungs $[33,34]$. Therefore, it appears the in vitro setup of Figure $1 \mathrm{~A}$ is unique in that it simultaneously shows cell behavior phenomena consistent with the literature - invasive cancer cell migration to fibroblasts and ASC migration towards invasive cancer cells. 


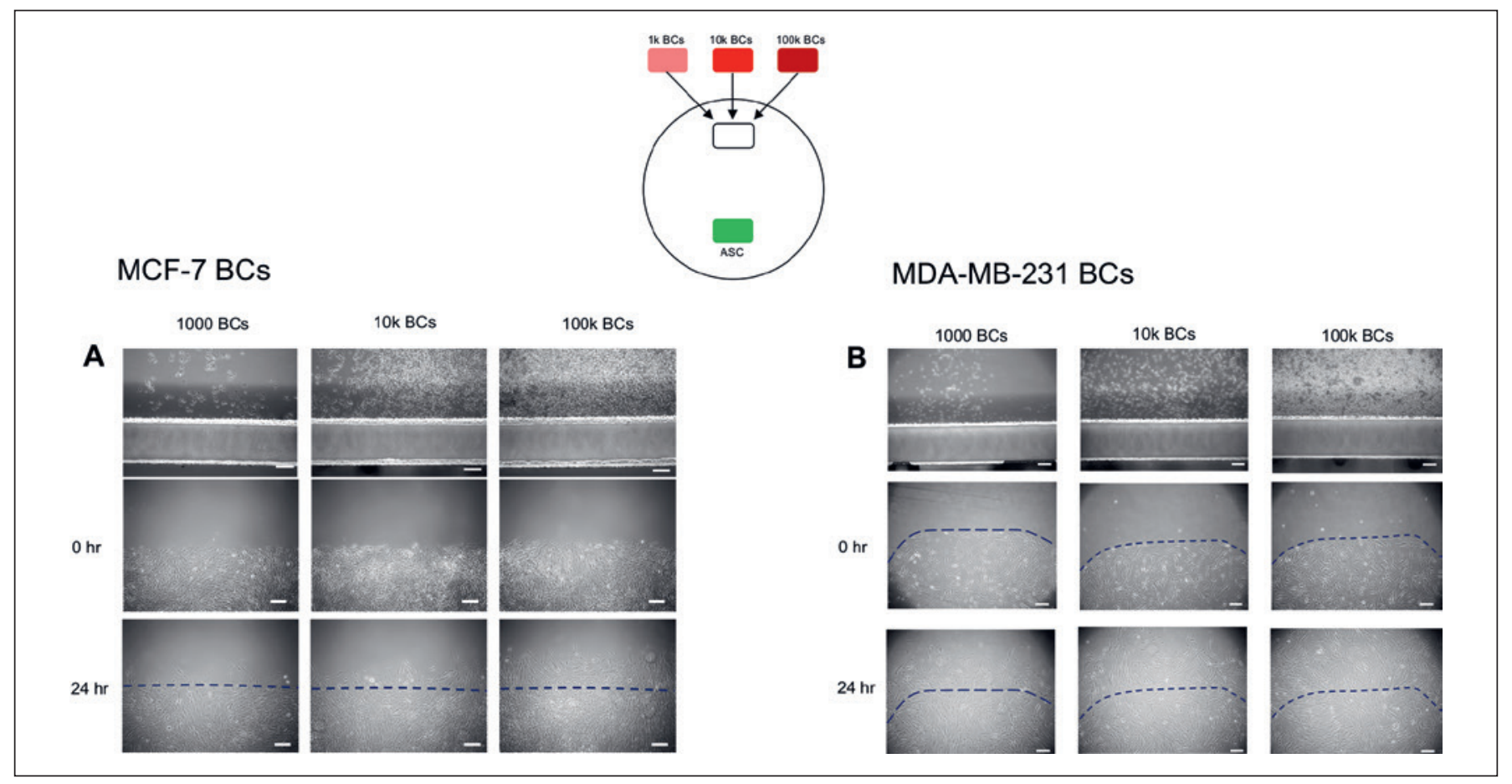

Fig. 5. These data represent results from the in vitro setup described in Figure 1C. BCs were seeded in the topmost chamber, with ASCs seeded in the chamber opposite. The number of BCs seeded varied from 1,000 to 10,000 to 100,000 , and the chamber holding the BCs was left in place, allowing paracrine interaction. A Analysis of cell migration in response to increasing numbers of MCF-7 cells between 0 and $24 \mathrm{~h}$. Blue dotted lines represent the original boundaries of the ASC chamber. B Analysis of cell migration in response to increasing numbers of MDA-MB-231 cells between 0 and $24 \mathrm{~h}$. Blue dotted lines represent the original boundaries of the ASC chamber.

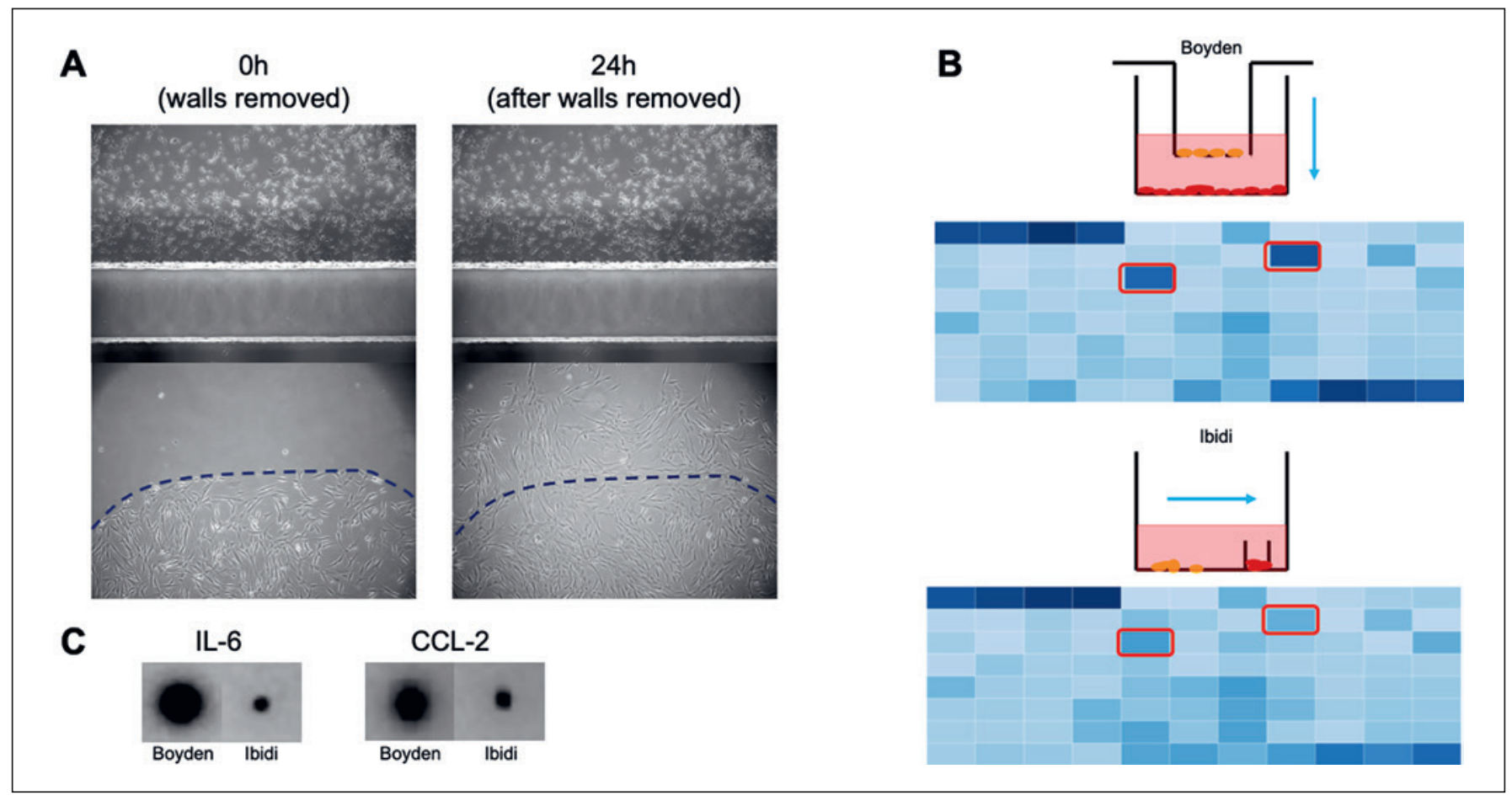

Fig. 6. A Brightfield images show migration of ASCs at $24 \mathrm{~h}$ throughout the incubation time (media for cytokine array was taken at 48 h). B Top: schematic shows the traditional Boyden chamber arrangement. Yellow ASCs were seeded in the chamber, and red MDA-MB-231 cells were seeded below. The blue arrow shows the direction of ASC migration. Bottom: images shows the novel assay arrangement. Heat maps show an overview of the differences in cytokine detection in the media at $48 \mathrm{~h}$. C Isolated images of the two most different cytokines between the assays, IL-6 and CCL-2. 
A causative clinical study linking breast cancer recurrence after reconstruction with ASC behavior does not exist. However, when isolated in vitro, ASCs and BCs interact in pro-oncogenic, pro-angiogenic ways. One study from 2017 used invasion, angiogenic, and transwell migration co-cultures of cancer cells with ASCs to suggest "oncological risk" of fat grafting [15]. The authors observed that co-cultured ASCs develop an advantageous secretome for BCs. The conclusion is not only surgical caution when grafting fat into a postcancer zone, but also there is even the recommendation of adding to the patient consent form the increased risk of relapse, cancer development, or dissemination of existing cancer with ASCbased reconstruction [15]. A separate study used BCs and ASCs from the same patient in a paracrine co-culture model, observed increased migratory behavior of cancer cells, and concluded that ASCs might have a negative, stimulatory effect on remnant cancer cells in the patient [16]. In vivo, renal capsule injections of ASC + MDAMB-231, compared to MDA-MB-231 alone, result in larger, more invasive tumors, giving evidence to the hypothesis that juxtacrine contact of ASCs and MDAMB-231 cells provokes the development of breast cancer tumors [35].

One study has shown that irradiating the ASCs before culturing with BCs slows the metabolic and clonal survival of the cancer. This effect was also transmitted via irradiated ASC-conditioned media on cancer cells, confirming the juxtacrine and paracrine impact of irradiated ASCs on cancer. This study also poses interesting questions about the status of native ASCs in breast fat after irradiation [36].

Numerous in vivo studies point at cancer circuitry stimulation by ASCs, through orthotopic injections of tumor cells with ASCs [37] or co-grafting of fat with cancer cells [38]. Contrarily, certain in vivo research exists which shows an inhibitory effect on MDA-MB-231 adenocarcinoma development by ASCs via PARP cleavage [39]. This study hints at the alternate, anti-oncogenic role of ASCs in breast cancer. Similarly, co-culture of ASCs and pancreatic cancer cells showed cancer cell death by stalling the cell cycle [40]. Importantly, one study involving ASCs and BCs acknowledges that ASCs are not tumorigenic, in that they lack the ability to convert a normal epithelial cell line to a malignant one [14]. This implies that the impact of the ASC is more pronounced with a highly mutated, aggressive cancer - a concept which holds true for the data presented in this paper.

Congruent with these studies is the existing clinical data, which does not observe recurrence as a risk factor of fat grafting. Minor clinical studies exhibit no recurrence or complications [41]. The American Society of Plastic Surgeons (ASPS) Fat Graft Task Force also wrote that there is no increased risk with fat grafting for breast cancer recurrence [11]. Mirroring this, a prospective trial named RESTORE-2 showed no significant risk of recurrence in women reconstructed even with cell-assisted lipotransfer - a procedure involving adding surplus autologous ASCs to the liposuction aspirate before it is grafted [42]. In a study with a longer follow-up, there was no recurrence observed after 10 years in patients with fat grafting postcancer treatments [43]. Patients who had previously been treated for primary invasive breast cancer were fat grafted and showed no increased rates of recurrence [44]. These clinical data might be somewhat explained by the novel ASC migration study described in this paper. Given the fact that the novel assay and Boyden chamber assay were essentially identical, but for the physical construction of the cell populations, the novel assay showed a cytokine profile which is much less oncogenic one that is congruent with the clinical literature. IL- 6 is a known pleotropic driver of breast cancer (chemotaxis of T cells and monocytes is an upstream activator of STAT3, a pro-angiogenic through VEGF, and a pro-survival through Bcl-xL) [45]. Meanwhile, CCL2 is a powerful chemoattractant for pro-inflammatory monocytes [46]. In the Boyden chamber assay, both IL-6 and CCL2 kickstart oncogenic sequalae, which could alter in vitro data, to show an oncogenic profile which may not be accurate.

In the course of this experimental plan, we analyzed cell-cell interaction in a way previously undescribed in the literature. To our knowledge, there exists no clear trophic evidence of ASCs migrating towards invasive BCs in vitro, as the canonical transmembrane assays make the observation of this dynamic impossible [15, 47]. Similarly, we generated a migration assay which provides results which are significantly less oncogenic than those of the commonly accepted migration assay. The clinical evidence shows a lack of postoperative complications and sequalae associated with breast cancer fat grafting [48], which can can be explained by redesign of in vitro migration analyses. Broadly speaking, implementation of assays which inherently bias against ASCs in a pro-oncogenic manner should be reconsidered.

Given the tropism of ASCs towards MDA-MB-231 cells, and the lack of clinical evidence for ASC-related relapse, it is prudent to consider the presence of any real risk of this cell attraction before ruling out a valuable plastic surgical procedure.

\section{Acknowledgments}

The authors would like to thank Mrs. Ursula Hopfner and Ms. Manuela Kirsch for lab technical support. 


\section{Statement of Ethics}

This research was performed within the boundaries of ethical principles.

\section{Disclosure Statement}

The authors have no conflicts of interest to declare.

\section{Funding Sources}

This study was supported by the Translational Medicine Program of the TUM School of Medicine and by a grant from the TUM Commission of Clinical Research to Dominik Duscher.

\section{Author Contributions}

M.A.S. and E.B.: conception of the model, protocol creation, experimental execution, and writing. C.M.M.: experimental execution. H.-G.M.: oversight of the project and advisor for manuscript writing. D.D.: oversight of the project, experimental design, and writing.

\section{References}

1 Rizvi SB, Yang SY, Green M, Keshtgar M, Seifalian AM. Novel POSS-PCU Nanocomposite Material as a Biocompatible Coating for Quantum Dots. Bioconjug Chem. 2015 Dec; 26(12):2384-96.

2 Brett E, Zielins ER, Luan A, Ooi CC, Shailendra S, Atashroo D, et al. Magnetic Nanoparticle-Based Upregulation of B-Cell Lymphoma 2 Enhances Bone Regeneration. Stem Cells Transl Med. 2017 Jan;6(1):151-60.

3 Momin EN, Vela G, Zaidi HA, Quiñones-Hinojosa A. The Oncogenic Potential of Mesenchymal Stem Cells in the Treatment of Cancer: Directions for Future Research. Curr Immunol Rev. 2010 May;6(2):137-48.

4 McLean AK, Stewart C, Kerridge I. Untested, unproven, and unethical: the promotion and provision of autologous stem cell therapies in Australia. Stem Cell Res Ther. 2015 Feb;6(1): 33.

5 Veres A. Low incidence of off-target mutations in individual CRISPR-Cas9 and TALEN targeted human stem cell clones detected by whole-genome sequencing. Cell Stem Cell. 2014 Jul;15(1):27-30.

6 Bora P, Majumdar AS. Adipose tissue-derived stromal vascular fraction in regenerative medicine: a brief review on biology and translation. Stem Cell Res Ther. 2017 Jun; 8(1):145.

7 Tan SS, Ng ZY, Zhan W, Rozen W. Role of Adipose-derived Stem Cells in Fat Grafting and Reconstructive Surgery. J Cutan Aesthet Surg. 2016 Jul-Sep;9(3):152-6.

8 Gabriel A, Champaneria MC, Maxwell GP. Fat grafting and breast reconstruction: tips for ensuring predictability. Gland Surg. 2015 Jun; 4(3):232-43.

9 Zhao L, Johnson T, Liu D. Therapeutic angiogenesis of adipose-derived stem cells for ischemic diseases. Stem Cell Res Ther. 2017 Jun; $8(1): 125$.

10 Chang Q, Lu F. A novel strategy for creating a large amount of engineered fat tissue with an axial vascular pedicle and a prefabricated scaffold. Med Hypotheses. 2012 Aug;79(2): 267-70.

11 Myckatyn TM, Wagner IJ, Mehrara BJ, Crosby MA, Park JE, Qaqish BF, et al. Cancer Risk after Fat Transfer: A Multicenter Case-Cohort Study. Plast Reconstr Surg. 2017 Jan; 139(1):11-8.
12 Freese KE, Kokai L, Edwards RP, Philips BJ, Sheikh MA, Kelley J, et al. Adipose-derived stems cells and their role in human cancer development, growth, progression, and metastasis: a systematic review. Cancer Res. 2015 Apr;75(7):1161-8.

13 Bielli A, Scioli MG, Gentile P, Agostinelli S, Tarquini C, Cervelli V, et al. Adult adiposederived stem cells and breast cancer: a controversial relationship. Springerplus. 2014 Jul; 3(1):345

14 Eterno V, Zambelli A, Pavesi L, Villani L, Zanini V, Petrolo G, et al. Adipose-derived Mesenchymal Stem Cells (ASCs) may favour breast cancer recurrence via $\mathrm{HGF} / \mathrm{c}$ Met signaling. Oncotarget. 2014 Feb;5(3): 613-33.

15 Koellensperger E, Bonnert LC, Zoernig I, Marmé F, Sandmann S, Germann G, et al. The impact of human adipose tissue-derived stem cells on breast cancer cells: implications for cell-assisted lipotransfers in breast reconstruction. Stem Cell Res Ther. 2017 May;8(1): 121

16 Charvet HJ, Orbay H, Harrison L, Devi K, Sahar DE. In Vitro Effects of Adipose-Derived Stem Cells on Breast Cancer Cells Harvested From the Same Patient. Ann Plast Surg. 2016 May;76 Suppl 3:S241-5.

17 Shammas RL, Fales AM, Crawford BM, Wisdom AJ, Devi GR, Brown DA, et al. Human Adipose-Derived Stem Cells Labeled with Plasmonic Gold Nanostars for Cellular Tracking and Photothermal Cancer Cell Ablation. Plast Reconstr Surg. 2017 Apr;139(4):900e$10 \mathrm{e}$.

18 Jerby L, Wolf L, Denkert C, Stein GY, Hilvo M, Oresic M, et al. Metabolic associations of reduced proliferation and oxidative stress in advanced breast cancer. Cancer Res. 2012 Nov;72(22):5712-20.

19 Kronowitz SJ, Mandujano CC, Liu J, Kuerer HM, Smith B, Garvey P, et al. Lipofilling of the Breast Does Not Increase the Risk of Recurrence of Breast Cancer: A Matched Controlled Study. Plast Reconstr Surg. 2016 Feb; 137(2):385-93.

20 Petit JY, Botteri E, Lohsiriwat V, Rietjens M, De Lorenzi F, Garusi C, et al. Locoregional recurrence risk after lipofilling in breast cancer patients. Ann Oncol. 2012 Mar;23(3): $582-8$
21 Klopp AH, Lacerda L, Gupta A, Debeb BG, Solley T, Li L, et al. Mesenchymal stem cells promote mammosphere formation and decrease E-cadherin in normal and malignant breast cells. PLoS One. 2010 Aug;5(8):e12180.

22 Martin FT, Dwyer RM, Kelly J, Khan S, Murphy JM, Curran C, et al. Potential role of mesenchymal stem cells (MSCs) in the breast tumour microenvironment: stimulation of epithelial to mesenchymal transition (EMT). Breast Cancer Res Treat. 2010 Nov;124(2):317-26.

23 Poczobutt JM, Tentler J, Lu X, Schedin PJ, Gutierrez-Hartmann A. Benign mammary epithelial cells enhance the transformed phenotype of human breast cancer cells. BMC Cancer. 2010 Jul;10(1):373.

24 Arrigoni C, Bersini S, Gilardi M, Moretti M. In Vitro Co-Culture Models of Breast Cancer Metastatic Progression towards Bone. Int Mol Sci. 2016 Aug;17(9):E1405.

25 Samoszuk M, Tan J, Chorn G. Clonogenic growth of human breast cancer cells co-cultured in direct contact with serum-activated fibroblasts. Breast Cancer Res. 2005;7(3):R274-83.

26 Huang HC, Chang YJ, Chen WC, Harn HI, Tang MJ, Wu CC. Enhancement of renal epithelial cell functions through microfluidic-based coculture with adipose-derived stem cells. Tissue Eng Part A. 2013 Sep;19(17-18):2024-34.

27 Kraus A, Woon C, Raghavan S, Megerle K, Pham H, Chang J. Co-culture of human adipose-derived stem cells with tenocytes increases proliferation and induces differentiation into a tenogenic lineage. Plast Reconstr Surg. 2013 Nov;132(5):754e-66e.

28 Shi J, Liang J, Guo B, Zhang Y, Hui Q, Chang $\mathrm{P}$, et al. Adipose-derived stem cells cocultured with chondrocytes promote the proliferation of chondrocytes. Stem Cells Int. 2017;2017: 1709582.

29 Dwyer RM, Potter-Beirne SM, Harrington KA, Lowery AJ, Hennessy E, Murphy JM, et al. Monocyte chemotactic protein-1 secreted by primary breast tumors stimulates migration of mesenchymal stem cells. Clin Cancer Res. 2007 Sep;13(17):5020-7.

30 Ritter A, Friemel A, Fornoff F, Adjan M, Solbach C, Yuan J, et al. Characterization of adipose-derived stem cells from subcutaneous and visceral adipose tissues and their function in breast cancer cells. Oncotarget. 2015 Oct; 6(33):34475-93. 
31 Zhang Y, Daquinag A, Traktuev DO, AmayaManzanares F, Simmons PJ, March KL, et al. White adipose tissue cells are recruited by experimental tumors and promote cancer progression in mouse models. Cancer Res. 2009 Jun;69(12):5259-66.

32 Paino F, La Noce M, Di Nucci D, Nicoletti GF, Salzillo R, De Rosa A, et al. Human adipose stem cell differentiation is highly affected by cancer cells both in vitro and in vivo: implication for autologous fat grafting. Cell Death Dis. 2017 Jan;8(1):e2568.

33 Jin L, Han B, Siegel E, Cui Y, Giuliano A, Cui $\mathrm{X}$. Breast cancer lung metastasis: molecular biology and therapeutic implications. Cancer Biol Ther. 2018;19(10):858-68.

34 White ES. Lung extracellular matrix and fibroblast function. Ann Am Thorac Soc. 2015 Mar;12 Suppl 1:S30-3.

35 Walter M, Liang S, Ghosh S, Hornsby PJ, Li R. Interleukin 6 secreted from adipose stromal cells promotes migration and invasion of breast cancer cells. Oncogene. 2009 Jul; 28(30):2745-55.

36 Baaße A, Juerß D, Reape E, Manda K, Hildebrandt G. Promoting effects of adipose-derived stem cells on breast cancer cells are reversed by radiation therapy. Cytotechnology. 2018 Apr;70(2):701-11.
37 Wei HJ, Zeng R, Lu JH, Lai WF, Chen WH, Liu HY, et al. Adipose-derived stem cells promote tumor initiation and accelerate tumor growth by interleukin-6 production. Oncotarget. 2015 Apr;6(10):7713-26.

38 Tsuji W. An animal model of local breast cancer recurrence in the setting of autologous fat grafting for breast reconstruction. Stem Cells Transl Med. 2018 Jan;7(1):125-34.

39 Sun B, Roh KH, Park JR, Lee SR, Park SB, Jung JW, et al. Therapeutic potential of mesenchymal stromal cells in a mouse breast cancer metastasis model. Cytotherapy. 2009;11(3):28998, 1 p following 298.

40 Cousin B, Ravet E, Poglio S, De Toni F, Bertuzzi M, Lulka H, et al. Adult stromal cells derived from human adipose tissue provoke pancreatic cancer cell death both in vitro and in vivo. PLoS One. 2009 Jul;4(7):e6278.

41 Tsekouras A. Adipose-derived stem cells for breast reconstruction after breast surgery preliminary results. Case Reports Plast Surg Hand Surg. 2017 Apr;4(1):35-41.

42 Perez-Cano R, Vranckx JJ, Lasso JM, Calabrese C, Merck B, Milstein AM, et al. Prospective trial of adipose-derived regenerative cell (ADRC)-enriched fat grafting for partial mastectomy defects: the RESTORE-2 trial. Eur J Surg Oncol. 2012;38(5):382-9.
43 Delay E, Garson S, Tousson G, Sinna R. Fat injection to the breast: technique, results, and indications based on 880 procedures over 10 years. Aesthet Surg J. 2009 Sep-Oct;29(5):360-76.

44 Petit JY, Maisonneuve P, Rotmensz N, Bertolini F, Rietjens M. Fat Grafting after Invasive Breast Cancer: A Matched Case-Control Study. Plast Reconstr Surg. 2017 Jun;139(6):1292-6.

45 Gyamfi J, Eom M, Koo JS, Choi J. Multifaceted Roles of Interleukin-6 in AdipocyteBreast Cancer Cell Interaction. Transl Oncol. 2018 Apr;11(2):275-85.

46 Kitamura T, Qian BZ, Soong D, Cassetta L, Noy R, Sugano G, et al. CCL2-induced chemokine cascade promotes breast cancer metastasis by enhancing retention of metastasisassociated macrophages. J Exp Med. 2015 Jun; 212(7):1043-59.

47 Wu JH, Li M, Liang Y, Lu T, Duan CY. Migration of Adipose-derived Mesenchymal Stem Cells Stably Expressing Chondroitinase ABC In vitro. Chin Med J (Engl). 2016 Jul;129(13): 1592-9.

48 Prantl L, Rennekampff HO, Giunta RE, Harder Y, von Heimburg D, Heine N, et al. [Current perceptions of lipofilling on the basis of the new guideline on "Autologous Fat Grafting”]. Handchir Mikrochir Plast Chir. 2016 Dec;48(6):330-6. German. 